\title{
Seroprevalence of chlamydia trachomatis infection in Kashmiri women of reproductive age with mucopurulent cervicitis, infertility and ectopic pregnancy - a hospital based study
}

\author{
Qurat U. Hassan, Asma H. Mufti*, Samiya Mufti
}

Department of Obstetrics and Gynecology, L. D. Hospital, Kashmir, Jammu and Kashmir, India

Received: 21 December 2021

Revised: 17 January 2022

Accepted: 18 January 2022

*Correspondence:

Dr. Asma H. Mufti,

E-mail: asma.h.mufti14@gmail.com

Copyright: () the author(s), publisher and licensee Medip Academy. This is an open-access article distributed under the terms of the Creative Commons Attribution Non-Commercial License, which permits unrestricted non-commercial use, distribution, and reproduction in any medium, provided the original work is properly cited.

\begin{abstract}
Background: Chlamydia trachomatis is one of the most prevalent sexually transmitted infection worldwide. Objective was to find the seroprevalence of the Chlamydia trachomatis infection in women who suffer from infertility, mucopurulent cervicitis and ectopic pregnancy and to investigate the possible role of the chlamydial serology as a screening test by detection of the anti-Chlamydia IgG antibodies using enzyme-linked immunosorbent assay (ELISA). Methods: 160 women who attended the gynecology outpatient department (OPD) at a tertiary care hospital were screened for presence of chlamydia trachomatis IgG antibodies. Patients were categorized based on clinical diagnosis in: group I comprising of 120 patients [40 patients in each sub group - mucopurulent cervicitis (MPC); infertility; and ectopic pregnancy]; and group II comprising fertile women with no clinical signs and symptoms of mucopurulent cervicitis and no history of ectopic pregnancy and infertility. Patients were screened for IgG antibodies to Chlamydia trachomatis.

Results: In our study $32.5 \%$ women with mucopurulent cervicitis were positive for Chlamydia trachomatis immunoglobulin $\mathrm{G}$ (CT IgG). In the infertile group, $22.5 \%$ of women were positive for chlamydia IgG antibodies. $30 \%$ of ectopic pregnancies were positive for chlamydia trachomatis IgG. Out of 40 patients who were taken as controls, $7.5 \%$ screened positive for Chlamydia IgG antibodies. Seroprevalence of Chlamydia trachomatis was $23.12 \%$ in our study.

Conclusions: Our study has shown that significant proportion of our population harbor Chlamydia trachomatis. So, it becomes imperative that health and screening programs be employed to prevent spread of this infection and its long term sequelae in women of childbearing age.
\end{abstract}

Keywords: Pelvic inflammatory disease, MPC, CT IgG

\section{INTRODUCTION}

Chlamydia is small gram-negative eubacteria - spherical or ovoid obligate intracellular bacteria that are ubiquitous. Intracellular parasitism of Chlamydia differentiates it from other bacteria. Chlamydia trachomatis is the most common cause of sexually transmitted bacterial infection worldwide. ${ }^{1}$ Females share the major burden of the disease. Recent studies from India have revealed the prevalence of Chlamydia trachomatis in young females to be $43 \%$ in the gynecology outpatient department (OPD) and $18.9 \%$ in patients with sexually transmitted diseases. ${ }^{2,3}$ Asymptomatic and untreated genital infections have serious implications on the reproductive health of women. It is also associated with 3-6 fold increase in transmission of human immunodeficiency virus (HIV) and is considered a risk factor for development of cervical carcinoma. $^{4}$ 
The most important clinical manifestations of Chlamydia trachomatis infection in women include mucopurulent cervicitis (MPC), acute urethral syndrome, pelvic inflammatory disease (PID), postpartum endometritis, ectopic pregnancy and tubal infertility. ${ }^{5}$

Chlamydia trachomatis has been isolated from the cervix of $5 \%$ to $12 \%$ of healthy non pregnant women and $2 \%$ to $20 \%$ of pregnant women. ${ }^{6-8}$ It has also been isolated from the cervix of up to $36 \%$ of women with acute PID and in $86 \%$ from fallopian tubes in women with acute PID and positive cervical culture for Chlamydia trachomatis. ${ }^{9,10}$ Serological studies further support the role of Chlamydia in acute PID. MHrdh et al reported that $80 \%$ of women with acute salpingitis had Chlamydia trachomatis antibodies, and that $37 \%$ had a 4-fold change in IgG antibody titer. ${ }^{11}$ Women with PID have a 4 to 7 -fold increased risk of infertility, and each episode of PID approximately doubles the risk. ${ }^{6}$

Ectopic pregnancy is a relatively common condition among women of childbearing age and comprises $1-3 \%$ of reported pregnancies.

Tubal factor infertility is one of the main causes of involuntary childlessness in women. $^{11}$ Sexually transmitted diseases (STDs) are believed to play an important role in the increase in infertility, particularly when it is caused by tubal factors. ${ }^{12}$ Female infertility is attributed to the tubal factors in about $14-38 \%$ of the cases. The tubal damage is presumed to be secondary to salpingitis, with a two-third of the subjects being asymptomatic while the remaining one third present with symptoms. The Chlamydial infection produces less severe symptoms than other sexually transmitted infections. ${ }^{13}$ The deceptively mild symptoms of Chlamydia trachomatis allow the infection to go unnoticed, with minimal patient awareness until the more severe secondary or the tertiary symptoms develop. Serious sequelae like acute salpingitis and pelvic inflammatory disease often occur in association with repeated or persistent infection. Chlamydia trachomatis may cause intraluminal adhesions, fibrosis, hydrosalpinx and pelvic adhesions. Due to the serious consequences of these conditions, the Chlamydia trachomatis infection can lead not only to significant morbidity, but it can also affect a woman's fertility.

Several studies have demonstrated that tubal factor infertility was significantly associated with the serum antibodies to Chlamydia trachomatis, which resulted in infertility. ${ }^{14} \mathrm{~A}$ better understanding of the role of persistent Chlamydia trachomatis infection in tubal factor subfertility may be useful in optimizing the fertility workup by incorporating screening tests for persistent Chlamydia trachomatis infection, aiming to accurately estimate the risk of persistence and identify those women who are at highest risk of tubal pathology.

Due to the high prevalence rates of Chlamydia trachomatis and the asymptomatic course of infection, screening programs have been established in some industrialized countries to reduce the rate of PID and prevent development of post infectious sequelae. Serological testing of uncomplicated Chlamydia trachomatis infection of the lower genital tract has not been recommended, but antibody titers are especially high in women with PID. The infertility which was caused by Chlamydia trachomatis represented a preventable type of infertility, if it was detected early.

Hence, the present study aims to find the seroprevalence of the Chlamydia trachomatis infection in women who suffer from infertility, mucopurulent cervicitis and ectopic pregnancy and to investigate the possible role of the Chlamydial serology as a screening test by detection of the anti-Chlamydia IgG antibodies using enzyme linked immunosorbent assay (ELISA).

\section{METHODS}

This prospective observational study was carried out at Government Lalla Ded Hospital, an associated hospital of Government Medical College, Srinagar, India over a period of two years, from July 2019 to July 2021 after obtaining ethical clearance from hospital institutional ethical committee.

All Kashmiri women of reproductive age-group attending the gynecology OPD with mucopurulent cervicitis, infertility or ectopic pregnancy and were willing to participate in the study were included.

Exclusion criteria included post-menopausal women, prepubertal girls, women of other ethnic groups, and pregnant females with normal intra-uterine pregnancies.

This study was conducted to find the seroprevalence of Chlamydia trachomatis infection in women with MPC, infertility and ectopic pregnancy versus the seroprevalence of Chlamydia trachomatis infection in females with no apparent signs and symptoms of MPC and no history of infertility and ectopic pregnancy.

\section{Sample size}

A total of 160 women who attended the gynecology OPD, over a period of two years were screened for the presence of Chlamydia trachomatis $\mathrm{IgG}$ antibodies to detect a difference of $30 \%$ in prevalence of Chlamydia infection at a $95 \%$ confidence and $80 \%$ power (expected prevalence in asymptomatic group $=10 \%$ ).

Patients were categorized based on clinical diagnosis into 2 groups.

Group I comprising of 120 patients (40 patients in each sub group): I (a) women with MPC, I (b) women with infertility, and I (c) women with ectopic pregnancy. 
Group II comprising of fertile women with no clinical signs and symptoms of MPC and no history of ectopic pregnancy and infertility.

Written informed consent was taken from all the participants of the study and venous blood samples from all these women were collected and screened for IgG antibodies to Chlamydia trachomatis, using the Calbiotech Chlamydia IgG kit based on ELISA. ${ }^{15-17}$

\section{RESULTS}

In our study, out of 40 patients with MPC, 13 patients were found positive for Chlamydia trachomatis IgG antibodies i.e. $32.5 \%$. 9 out of 40 patients with infertility were positive for Chlamydia trachomatis igG i.e. $22.5 \%$. Out of 40 patients with ectopic pregnancy, 12 screened positive for Chlamydia $\mathrm{IgG}$ i.e. $30 \%$. Out of 40 women taken as controls, 3 women were also found to be positive for Chlamydia trachomatis $\operatorname{IgG}$ antibodies i.e. 7.5 percent controls were also positive. $56.7 \%$ of women who were positive for CT IgG antibodies were from rural areas. Majority of patients who screened positive belonged to lower to upper middle socioeconomic status. In our study the overall seroprevalence of Chlamydia trachomatis was $23.12 \%$.

Out of 40 patients with MPC, 13 patients were found positive for Chlamydia trachomatis $\mathrm{IgG}$ antibodies i.e. $32.5 \%$ (Table 1).

Table 1: Seroprevalence of Chalymdia IgG in MPC.

\begin{tabular}{|llll|}
\hline IgG & N & Percentage & P value \\
\cline { 1 - 2 } IgG +ve & 13 & 32.5 & \\
\cline { 1 - 2 } IgG -ve & 27 & 67.5 & \\
\cline { 1 - 2 } Total & 40 & 100 & \\
\hline
\end{tabular}

9 out of 40 patients with infertility were positive for Chlamydia trachomatis IgG i.e. 22.5\% (Table 2).

Table 2: Seroprevalence of Chalymdia IgG in infertile women.

\begin{tabular}{|llll|}
\hline IgG & $\mathbf{N}$ & Percentage & P value \\
\cline { 1 - 2 } IgG +ve & 9 & 22.5 & \\
\cline { 1 - 2 } IgG -ve & 31 & 77.5 & 0.001 \\
\hline Total & 40 & 100 & \\
\hline
\end{tabular}

Out of 40 patients with ectopic pregnancy, 12 screened positive for Chlamydia IgG i.e. $30 \%$ (Table 3).

Out of 40 women taken as controls, 3 women were also found to be positive for Chlamydia trachomatis IgG antibodies i.e. 7.5 percent controls were also positive (Table 4).

$56.7 \%$ of women who were positive for CT IgG antibodies were from rural areas (Figure 1).
Table 3: Seroprevalence of Chalymdia IgG in ectopic pregnancies.

\begin{tabular}{|llll|}
\hline IgG & $\mathbf{N}$ & Percentage & P value \\
\cline { 1 - 2 } IgG +ve & 12 & 30 & \\
\cline { 1 - 2 } IgG -ve & 28 & 70 & \\
\hline Total & 40 & 100 & \\
\hline
\end{tabular}

Table 4: Seroprevalence of Chalymdia IgG in controls.

\begin{tabular}{|lll|}
\hline IgG & N & Percentage \\
\hline IgG +ve & 3 & 7.5 \\
\hline IgG -ve & 37 & 92.5 \\
\hline Total & 40 & 100 \\
\hline
\end{tabular}

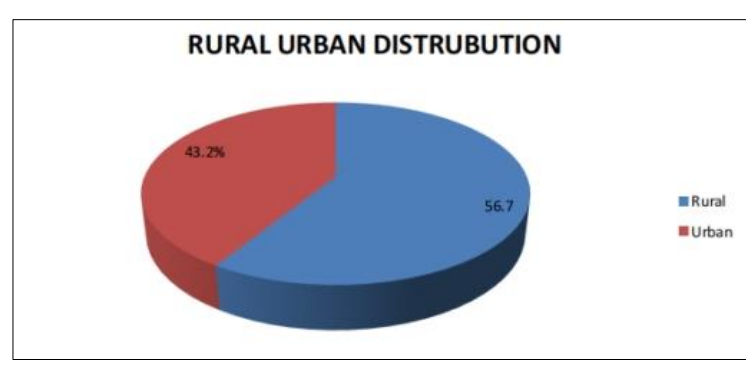

Figure 1: Rural urban distribution.

Majority of patients who screened positive belonged to lower to upper middle socioeconomic status (Figure 2). In our study the overall seroprevalence of Chlamydia trachomatis was $23.12 \%$ (Table 5).

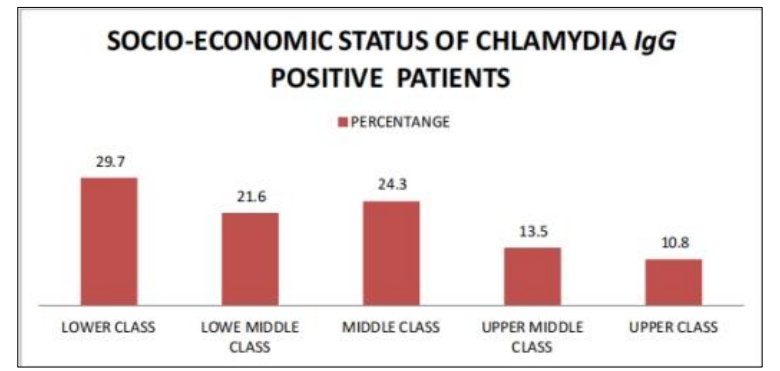

Figure 2: Socio-economic status of Chlamydia IgG positive patients.

Table 5: Overall prevalence of Chlamydia trachomatis infection in present study.

\begin{tabular}{|c|c|c|c|c|}
\hline Study group & $\begin{array}{l}\text { Total } \\
\text { no. of } \\
\text { case }\end{array}$ & $\begin{array}{l}\text { CT } \\
\text { IgG } \\
+ \text { ve } \\
\text { cases }\end{array}$ & $\begin{array}{l}\text { CT } \\
\text { IgG - } \\
\text { ve } \\
\text { cases }\end{array}$ & $\begin{array}{l}\% \text { of +ve } \\
\text { cases }\end{array}$ \\
\hline $\begin{array}{l}\text { Ectopic } \\
\text { pregnancies }\end{array}$ & 40 & 12 & 28 & 30 \\
\hline Infertility & 40 & 9 & 31 & 22.5 \\
\hline MPC & 40 & 13 & 27 & 32.5 \\
\hline Controls & 40 & 3 & 37 & 7.5 \\
\hline Total & 40 & 37 & 123 & 23.12 \\
\hline
\end{tabular}




\section{DISCUSSION}

Chlamydia trachomatis is one of the most prevalent sexually transmitted infection worldwide. ${ }^{18}$ Long term sequelae of Chlamydia trachomatis infection include pelvic inflammatory disease, tubal factor infertility and increased risk of ectopic pregnancy. Chlamydia trachomatis is a mucosal pathogen that establishes infection within epithelial cells in both the lower and upper genital tract of women. ${ }^{19} \mathrm{Up}$ to $70 \%$ of women with Chlamydia trachomatis infection have silent infection and in the majority of cases with such an infection the disease is self-limited.

Out of the 40 patients in the MPC group, $32.5 \%$ women were positive for Chlamydia trachomatis IgG. Venkatesh et al also conducted a study to found $17.2 \%$ of women with MPC positive for Chlamydia trachomatis $I g G$ antibodies. ${ }^{20}$ Similar results were present in the study done by Hill et al. ${ }^{21}$ Among the 40 patients with infertility, $22.5 \%$ of infertile women were positive for Chlamydia trachomatis IgG. Rabei, Mohammad, El Guindy. ${ }^{22}$ Also conducted a study to found that $32.5 \%$ of women positive for Chlamydia trachomatis $\mathrm{IgG}$ antibodies in the infertile group. Lindgren, Khilstorm did a similar study to find $40 \%$ of women positive for Chlamydia trachomatis $\operatorname{Ig} G$, which is higher as compared to our study. ${ }^{23}$ Similar results were found by Venkatesh $\mathrm{BMS}^{20}$ et al in their study where they found $17.2 \%$ women positive for Chlamydia trachomatis $\operatorname{Ig} G$ antibodies in the infertile group.

$30 \%$ of patients with ectopic pregnancies were positive for Chalymdia. Khilstorm et also conducted a study to find $33 \%$ of women with ectopic pregnancies had positive Chlamydia $\operatorname{Ig} G$ antibodies. Similar results were found by Guindy, Rabei. ${ }^{22,23}$

In our study, out of 40 controls, three tested positive for CT IgG antibodies i.e. $7.25 \%$ of controls also tested positive.

Similar results were also present in the studies done by Guindy, Rabei and Emad and El Tammey. ${ }^{19,22}$

Rural predominance was found in our study. $56.7 \%$ of women who were positive for CT IgG antibodies were from rural areas and $43.2 \%$ women were from urban areas. Majority of patients who screened positive for Chlamydia trachomatis IgG antibodies belonged to lower to upper middle socioeconomic status. In our study the overall seroprevalence of Chlamydia trachomatis was $23.12 \%$.

Limitations of this study is that many patients with this infection are asymptomatic and may not report to gynecological OPD and hence are unreported.

\section{CONCLUSION}

Chlamydia trachomatis is one of the most common organisms causing pelvic inflammatory disease, with long term sequelae in the form of ectopic pregnancy and infertility in women of childbearing age. It has also enormous health care and economic implications as well as social and psychological impacts on women bearing this infection. Our study has shown that significant proportion of Kashmiri women also harbor this infection, with overall seroprevalence of $23.12 \%$ in our study.

Also significant numbers of asymptomatic women carry this infection and hence do not seek medical attention, further complicating the outcome. So it becomes imperative that health and screening programs be employed to prevent the spread of this infection and it's long term residual sequelae in Kashmiri women of childbearing age.

Funding: No funding sources

Conflict of interest: None declared

Ethical approval: The study was approved by the Institutional Ethics Committee

\section{REFERENCES}

1. World Health Organization. Global prevalence and incidence of selected curable sexually transmitted diseases: Overview and estimates. 2011. Available at: https://www.google.com/url?sa=t\&rct=j\&q=\&esrc=s $\&$ source $=$ web $\& c d=\& c a d=$ rja $\&$ uact $=8 \&$ ved $=2$ ahUK EwjZkYbFz8z1AhVC83MBHUD1AGMQFnoECA wQAQ\&url=https\%3A\%2F\%2Fapps.who.int\%2Firis $\% 2$ Fhandle\%2F10665\%2F66818\&usg=AOvVaw27o Yw2BM4sM5_AJBApUAdv. Accessed on 15 October 2021.

2. Singh V, Rastigoi S, Garg S, Kapur S, Kumar H, Salhem S, et al. Polymerase chain reaction for detection of endocervical Chlamydia trachomatis infection in women attending gynaecology OPD in in India. Acta Cytol. 2002;46:540-4.

3. Joyee AG, Thyagarajan SP, Sowmya B, Venkatesh C, Ganapathy M. Need for specific and routine strategy for the diagnosis of genital chlamydial infection among patient with STD in India. Indian J Med Res. 1997;10:60-84.

4. Fleming DT, Wasserheit JN. From epidemiological synergy to public health policy and practice. The contribution of other sexually transmitted disease to sexual transmission of HIV infection. Sex Transm Infect. 1999;75:3-17.

5. Paavonen J. Clinical manifestations and therapy of genital chlamydial infections in women. In: Proceedings of the European Society for Chlamydia Research, Bologna, Italy: Societa Editrice Esculapio. 1988;152-5.

6. McCormack WM, Alpert S, McComb DE, et al. Fifteen-months follow-up study of women infected with Chlamydia trachomatis, $\mathrm{N}$ Engl $\mathrm{J}$ Med. 1979;300:123-5.

7. Osser S, Persson K. Epidemiologic and serodiagnostic aspects of chlamydial salpingitis. Obstet Gynecol. 1982;59:206-9. 
8. Wager GP, Martin DH, Kontsky L. Relationship to route of delivery and to antepartum Chlamydia trachomatis infections. Am J Obstet Gynecol. 1980;158:1028-33.

9. Mårdh PA, Ripa T, Svensson L, Weström L. Chilamydia trachomatis infection in patients with acute salpingitis. N Engl J Med. 1977;296(24):13779.

10. MBrdh PA. An overview of infections agents of salpingitis. Am J Obstet Gynecol. 1980;138:933-51.

11. Dabekausen YA, Evers JL, Land JA, Stals FS. The Chlamydia trachomatis antibody testing is more accurate than hysterosalpingography in predicting the tubal factor infertility. Fertil Steril. 1994;61:833-7.

12. Cates W. Tubal infertility: An ounce of (more specific) prevention (editorial). JAMA. 1987;257:2480.

13. Malik A, Jain S, Hakim S, Shukla I, Rizvi M. The Chlamydia trachomatis infection and female infertility. Indian J Med Res. 2006;770-5.

14. Mardh PA, Wolner-Hansseen P. Three novel manifestations of Chlamydia trachomatis infection: Endometritis, Perihepatitis and meningoencephalitis. Infection. 1982;10:57-60.

15. Konstantinou GN. Enzyme - linked immunosorbent Assay (ELISA). Methods Mol Biol. 2017;1592:79-94.

16. Maghsoudlou P, Shah K. Enzyme -linked Immunsorbent Assay (ELISA); The basics. Br J Hosp Med (Lond). 2016;77(7).

17. Engvall E. The ELISA, Enzyme -linked Immunsorbent Assay. Clin Chem. 2010;56(2):31920.

18. Cárcamo CP, Campos PE, García PJ, Hughes JP, Garnett GP, Holmes KK; Peru PREVEN study team.
Prevalences of sexually transmitted infections in young adults and female sex workers in Peru: a national population-based survey. Lancet Infect Dis. 2012;12(10):765-73.

19. El-Tamamy EA, Mohamed AH, Hablas WR, ElRahman SHA. Al-Azhar Med J. 2020;49(1):229-40.

20. Venkatesh BMS, Vivekanand N, Rao R. Prevalence of chlamydia trachomatis infection in women with pelvic inflammatory disease, mucopurulent cervicitis and infertility in Hyderabad. J Cont Med A Dent. 2016;4(1):13-7.

21. Hillis SD, Owens LM, Marchbanks PA, Amsterdam LE, Mac Kenzie WR. Recurrent Chlamydia infections increase the risk of hospitalization for ectopic pregnancy and pelvic inflammatory disease. Am J Obstet Gynecol. 1997;176:103-7.

22. EL-Guindy A, Rabei N, Mohammed N, Hassan N. Prevalence of the anti-chlamydial antibodies in infertile women and its association with tubal factor infertility. Int J Obstet Gynaecol Res. 2016;3(4):31025.

23. Kihlstrtim E, Lindgren R, Ryden G. 2 Antibodies to Chlamydia trachomatis in women with infertility, pelvic inflammatory disease and ectopic pregnancy. Eur J Obstet Gynecol Reprod Biol. 1990;35:199-204.

Cite this article as: Hassan QU, Mufti AH, Mufti S. Seroprevalence of chlamydia trachomatis infection in Kashmiri women of reproductive age with mucopurulent cervicitis, infertility and ectopic pregnancy - a hospital based study. Int J Reprod Contracept Obstet Gynecol 2022;11:563-7. 